\title{
Prof. Dr. med. Joachim Schauer zum 75. Geburtstag
}

\section{Prof. Dr. med. Joachim Schauer on the Occasion of his $75^{\text {th }}$ Birthday}

Am 25. April 2014 feierte Professor Joachim Schauer seinen 75. Geburtstag, zu dem wir ihm gratulieren. Wir freuen uns, dass unser verehrter Hochschullehrer und früherer Chef bei guter Gesundheit sein darf. Wer erwartet hätte, dass er nur noch seinen Leidenschaften frönt, Gespräche über Musik (bei bekannter Vorliebe für Wagner und Mahler) bei einem Glas guten Rotwein führt und über die alten Zeiten philosophiert - hat weit gefehlt!

Professor Schauer ist nach wie vor sehr engagiert in der Patientenbetreuung, bringt seine Erfahrung im Kollegenkreis ein und ist dank seiner langjährigen Expertise als gefragter Gutachter tätig. Als Ehrenpräsident der von ihm mitbegründeten Mitteldeutschen Gesellschaft für Pneumologie (MDGP) und als früherer Präsident der Sächsischen Gesellschaft für Innere Medizin besucht und moderiert er auch heute noch Tagungen und ist dabei weiterhin angesehener Diskussionspartner.

Seine Gabe, teils gänzlich unterschiedliche Positionen integrativ und produktiv zusammenzufügen, waren ihm - gepaart mit Optimismus, Willensstärke und visionärer Kraft - in den schwierigen Jahren nach der politischen Wende in unserem Land und der damit verbundenen Umgestaltung auch der Universität Leipzig als gewählter Klinikdirektor und Prodekan und später als Medizinischer Vorstand des Universitätsklinikums eine große Hilfe. Er war der richtige Mann am richtigen Ort! Die Abteilung Pneumologie an der Medizinischen Klinik wurde unter seiner Leitung zu einem der führenden Zentren für Pulmonale Hypertonie Mitteldeutschlands und beherbergt eines der ersten Schlaflabore Sachsens.

Die ihm anvertraute Organisation und Gestaltung des 39. Kongresses der Deutschen Gesellschaft für Pneumologie in Leipzig im März 1998 waren für ihn und seine Mitarbeiter ein besonderes Anliegen. Professor Nikolaus Konietzko schrieb später darüber: „Es war ein glanzvoller Kongress, erst-
Bibliografie

Dol http://dx.doi.org/ 10.1055/s-0034-1365685 Pneumologie 2014; 68: 431 (c) Georg Thieme Verlag KG Stuttgart · New York ISSN 0934-8387

Korrespondenzadresse

Prof. Dr. med.

Gerhard Hoheisel

Praxis für Pneumologie/

Allergologie

August-Bebel-Str. 69

04275 Leipzig

gerhard.hoheisel@t-online.de

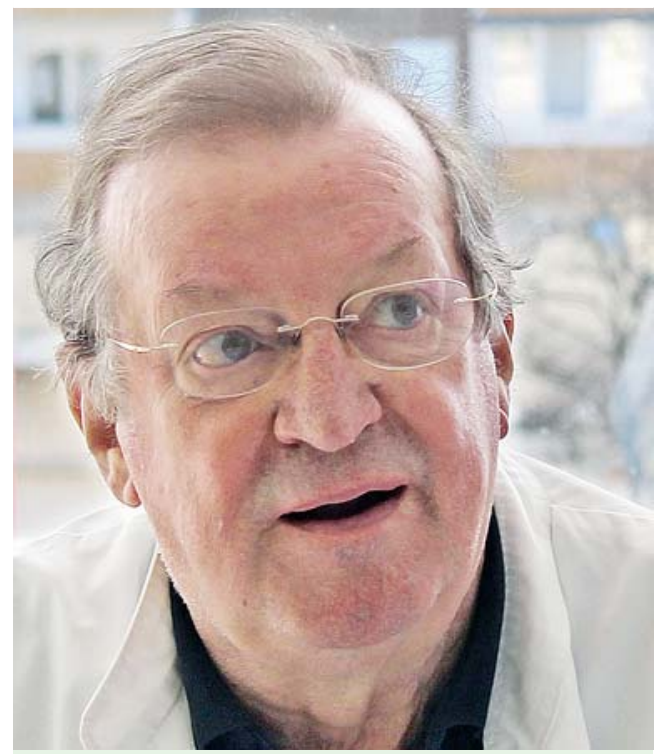

Prof. Dr. med. Joachim Schauer

Landschaften beigetragen zu haben, war für ihn eine Ermutigung von besonders hohem Wert.

Trotz seiner administrativen Kompetenzen und akademischen Meriten bewahrte sich Professor Schauer seine Bodenständigkeit, seine zwischenmenschliche Empathie und Güte. Er ist als Internist im allerbesten Sinne auch Generalist - uns als Arzt und Mensch ein Vorbild. Er förderte seine Mitarbeiter, gewährte ihnen Freiräume zur Profilierung auf nationaler und internationaler Ebene. Viele seiner Schüler und Mitarbeiter gestalten heute das Fachgebiet der Pneumologie nicht nur in Sachsen mit.

Wir wünschen ihm von Herzen ein Minimum an Sorgen und Beschwerden und ein Maximum an fortwährender Kreativität, Lebensfreude und Schaffenskraft im Kreis seiner Familie, Freunde und Kollegen.

Jörg Winkler, Lutz Steiniger, Matthias Vogtmann, Gerhard Hoheisel turierten wissenschaftlichen Sektionen durchgeführt. Die Tagung in Leipzig war perfekt organisiert, eingebettet in eine kühle ästhetische Architektur und eine warme menschliche Atmosphäre. Ihr Tagungspräsident, Joachim Schauer, hat damals Maßstäbe gesetzt“ [1]. Durch diesen Kongress zur Integration der in beiden Teilen unseres Landes unterschiedlich gewachsenen pneumologischen

\section{Literatur}

1 Konietzko N. Professor Dr. Joachim Schauer zur Vollendung seines 65. Lebensjahres. Pneumologie 2004; 58: $289-290$ 